\title{
Utilização de Energia Solar em Chuveiros de uma Creche do Município de Vassouras
}

\author{
Marcus Vinicius A. Macedo \\ Universidade Severino Sombra, CELCSAH, Curso de Pós-Graduação \\ em Gestão Pública Municipal, macedomarcus@uol.com.br \\ Carlos Eduardo Cardoso \\ Universidade Severino Sombra, CECETEN, Curso de Engenharia \\ Ambiental, cardoso221@yahoo.com.br
}

\begin{abstract}
Resumo. A utilização de água quente é um aspecto fundamental da civilização moderna. Assim, este trabalho apresentou um estudo preliminar sobre a viabilidade do aproveitamento da energia solar para aquecimento de água de uma creche do municipio de Vassouras-RJ. Mais especificamente, pretendeuse demonstrar que, com o uso de ferramentas de gestão de projetos, essa implantação possibilitará a redução de custos e a preservação do ambiente. Após as análises prévias, concluiu-se que no âmbito da administração pública, a instalação de aquecedores solares em creches municipais seria uma opção viável, já que, comprovadamente, pode-se reduzir os custos associados ao aquecimento da água, principalmente, daquela utilizada para o banho dos alunos e funcionários.
\end{abstract}

Palavras-Chave: Energia solar. Gestão de projetos. Creches. Administração pública. Aquecimento solar.

\section{Solar Energy use in a Vassouras}

\section{Daycare Showers}

\begin{abstract}
The hot water use is a fundamental aspect of modern civilization. This work presented a preliminary study on the feasibility of solar energy use for water heating at a daycare center in the Vassouras (RJ) city. More specifically, we sought to demonstrate that with the project management tools use, such deployment will enable cost reduction and environmental preservation. After the previous analysis, we concluded that within the administration, installation of solar heaters in a daycare would be a viable option, as shown can reduce the costs associated with heating water, especially one used to students and employees baths.
\end{abstract}


Keywords: Solar Energy. Project Management. Daycare. Public administration. Solar Heating.

\section{Introdução}

A utilização de água quente é um aspecto fundamental da civilização moderna. No Brasil, a principal maneira de se obter água quente para o banho se dá mediante uso de chuveiros elétricos, os quais possuem potência de $5 \mathrm{~kW}$ a $10 \mathrm{~kW}$. O uso desses equipamentos para aquecer a água faz com que o sistema elétrico nacional (geração, transmissão e distribuição) tenha que ser superdimensionado para garantir o fornecimento no horário de pico, que coincide com aquele utilizado para o banho.

No ano de 2004, o consumo de energia elétrica no setor residencial foi de 78,5 TWh, e cresce $3,0 \%$ em relação ao consumo de 2003, com atendimento a cerca de 46,8 milhões de consumidores. O setor residencial responde por $24 \%$ do consumo de energia elétrica no país. Neste setor, há uma participação média de $26 \%$ do consumo atribuído ao aquecimento de água, segundo o Programa Nacional de Conservação da Energia Elétrica (Procel). Desse modo conclui-se que apenas o aquecimento de água para banho em residências brasileiras é responsável por mais de 6,0\% de todo o consumo nacional de energia elétrica. (Brasil, 2009).

A Associação Brasileira de Refrigeração, Ar Condicionado, Ventilação e Aquecimento (Abrava, 2009) reforça que uma alternativa para diminuir o consumo de energia elétrica em aquecimento de água é popularizar o uso da energia solar para seu aquecimento. $\mathrm{O}$ mercado mundial de aquecedores solares começou a crescer a partir da década de 70, mas expandiu significativamente durante a década de 90 . Resultou desse crescimento, um aumento substancial de aplicações, da qualidade e dos modelos disponíveis.

Segundo Pereira e colaboradores (2006), o Brasil apresenta potencial bastante grande para a utilização do aquecimento solar, já que a irradiação incidente em qualquer região de seu território, supera os da maioria dos países da União Europeia.

Por aquecimento solar entende-se o aproveitamento da taxa de energia emitida pelo sol e recebida pela Terra. Essa energia é emitida em forma de radiação, capturada por placas coletoras e transformada em energia térmica, com o objetivo de aquecer um fluído de trabalho, sendo a água o mais comumente usado. Os sistemas de aquecimento solar são equipamentos basicamente compostos de coletores solares, reservatórios térmicos (boilers) e acessórios. O reservatório térmico e os coletores solares são interligados à rede de água fria, e quando há absorção de energia solar pelos coletores, a água é aquecida, o que provoca uma circulação que cessará quando o sistema entrar em equilíbrio térmico. Dependendo da montagem do sistema, essa circulação pode ser natural (termos sifão) ou auxiliada por uma bomba (circulação forçada). O aquecimento solar utiliza uma fonte de energia gratuita, limpa e inesgotável, o que torna sua utilização ecologicamente correta.

A economia proporcionada pela substituição dos aquecedores elétricos por sistemas de aquecimento solar é considerável, porém, o elevado investimento inicial é a principal dificuldade para a sua adoção em larga escala. De acordo com o Procel (Brasil, 2009), um chuveiro elétrico é responsável por $25 \%$ a $35 \%$ do gasto de eletricidade de uma casa e apresenta um consumo médio mensal de $120 \mathrm{kWh}$, considerando um chuveiro de $3500 \mathrm{~W}$, 
com 40 minutos de uso por dia (quatro banhos diários de 10 minutos cada). Esse volume de energia elétrica, para ser produzido, lança cerca de 31 quilogramas de dióxido de carbono $\left(\mathrm{CO}_{2}\right)$ na a atmosfera, o que em um ano totaliza 11 mil quilogramas de $\mathrm{CO}_{2}$ emitidos. Para contribuir com a redução da demanda por energia elétrica, o consumidor pode optar por utilizar energia renovável, como a solar, gerada por meio de painéis de aquecimento. Essa tecnologia é uma alternativa ambientalmente positiva para o consumidor, já que possibilita o banho com o mesmo conforto e menor emissão de gases de efeito estufa.

Outra razão para a escolha do uso da energia solar térmica é a de que o Brasil domina a tecnologia de aquecedores solares, com $100 \%$ dos equipamentos utilizados produzidos no país, com mão-de-obra e matérias-primas nacionais. Além disso, o uso do aquecedor solar permite ao Brasil tornar explicito o seu compromisso com o ambiente e, em particular, com o Protocolo de Kyoto. (Cepel, 2005).

Neste sentido, várias experiências positivas têm sido reportadas. Em São Paulo, a Lei $\mathrm{n}^{\circ} 11.228$, de 1982 determina a obrigatoriedade da instalação de aquecimento solar em várias tipologias de edificações, como residências, apartamentos, comércio, serviços e indústrias, escolas e creches. Em Niterói-RJ, a concessionária de energia (Ampla) iniciou, em maio de 2009, obras de eficiência energética em três creches públicas. A iniciativa faz parte do projeto Consciência Ampla Eficiente, e consiste na instalação de sistemas de aquecimento solar da água nestas unidades (Vitae Civilis, 2009; Energia Hoje, 2009). Nos Estados Unidos, a Sidwell Friends School, em Washington, é um exemplo de escola ecologicamente correta, pois incluiu o uso de energia mediante placas solares para o aquecimento da água usada em suas instalações (Martins, 2009).

Este trabalho visa apresentar um estudo preliminar sobre a viabilidade do aproveitamento da energia solar para aquecimento de água de uma creche do município de Vassouras-RJ. Mais especificamente, pretende demonstrar que a implantação desse recurso possibilitará a redução de custos e a preservação do ambiente.

\section{Materiais e Métodos}

O trabalho utilizou a Creche Leon Gilson (Figura 1), localizada em Barão de Vassouras (distrito de Vassouras), como campo de estudo.

A metodologia empregada para verificar a viabilidade da proposta foi a do Gerenciamento de Projetos de Desenvolvimento - GPD. (Pfeiffer, 2005). Para a conceituação, desenho, execução e avaliação do projeto foi utilizado um Quadro Lógico (Logical Framework).

As orientações básicas e a filosofia do projeto foram colocadas na Carta do Projeto e as atividades relacionadas foram estruturadas a partir da ferramenta Work Breakdown Structure (WBS). 


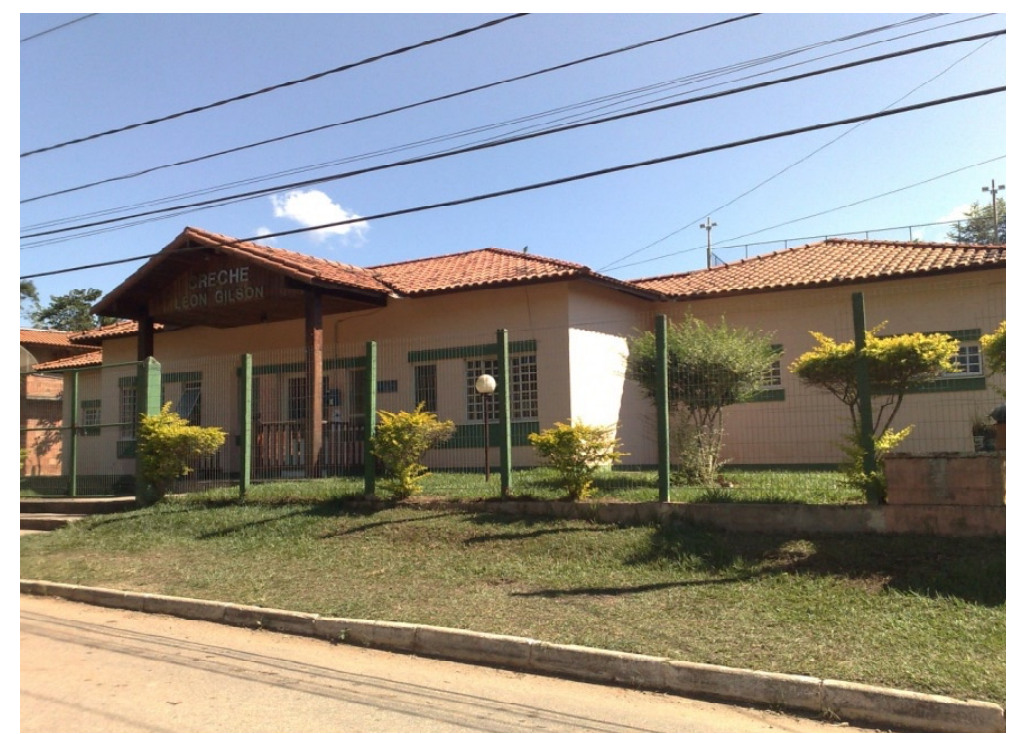

Figura 1. Vista parcial da Creche Leon Gilson em Barão de Vassouras

O sistema de aquecimento de água por energia solar utilizado como referência dispõe de instalações básicas deste tipo de equipamento. A circulação de água entre o coletor solar e o reservatório térmico acontece por termossifão e em conformidade com as recomendações do fabricante quanto aos materiais utilizados. Isolamento térmico, inclinação das tubulações, níveis do reservatório de água fria e quente e orientação e inclinação do coletor solar também estão de acordo com o preconizado pela Soletrol (2009). Um diagrama esquemático pode ser visto na Figura 2.

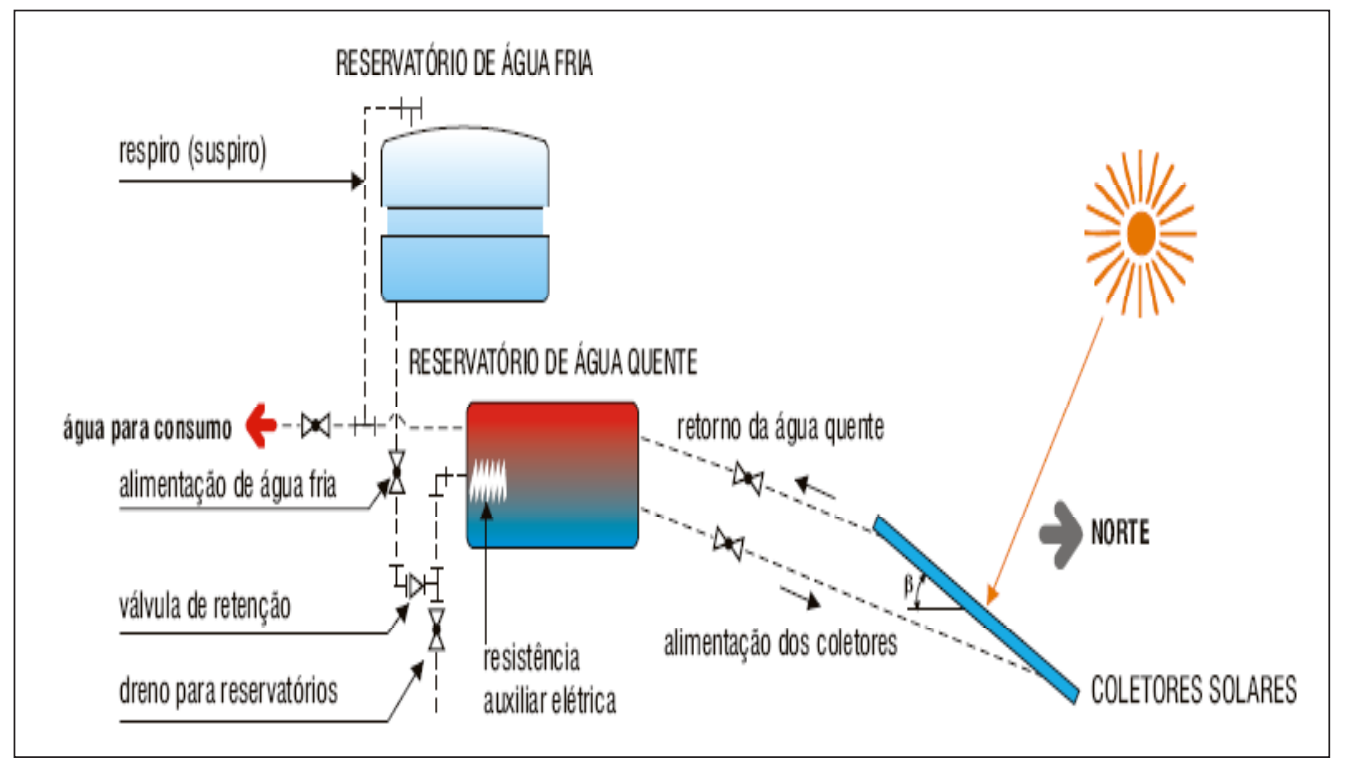

Figura 2. Sistema de aquecimento solar (fonte: SOLETROL, 2009). 


\section{Resultados e Discussão}

Vassouras tem uma rede pública de ensino com dezoito escolas e cinco creches municipais, perfazendo um total de 3878 alunos. Destes, 249 estão matriculados em creches com horário integral e 3629 em escolas do ensino fundamental. (Secretaria Municipal de Educação, 2009).

Com atendimento específico para crianças de seis meses a três anos de idade, a creche Leon Gilson atende em horário integral. Em 2009, teve 78 alunos matriculados e um montante de vinte e três funcionários.

O sistema de gerenciamento de projetos do GPD baseia-se em três elementos: o ciclo de vida do projeto, processos de gerenciamento e instrumentos de gerenciamento. $\mathrm{O}$ ciclo de vida do projeto é dividido em concepção, planejamento, implementação e finalização. Essa divisão traz a vantagem de focar melhor os processos necessários em cada fase, sem perder a visão geral. Os processos são organizados em entradas necessárias, atividades planejadas e saídas desejadas. Para a execução dos processos são necessários instrumentos gerenciais que visam facilitar, assegurar o gerenciamento e atingir os resultados desejados. O GPD traz diferenças essenciais em relação ao gerenciamento dos projetos de engenharia, dos quais se destacam a análise do ambiente e a percepção de que o "cliente" do projeto é a comunidade da creche.

O método GPD recomenda o uso da Árvore de Objetivos para a análise dos objetivos da proposta. Trata-se de um diagrama cujos objetivos são colocados como estados positivos. Desse modo, a relação causa-efeito é transformada em relação meio-fim. A Árvore de Objetivos visualiza uma situação ideal, a partir da qual são analisadas estratégias alternativas para o projeto. A Figura 3 mostra a Árvore de objetivos construída para este trabalho.

O Quadro Lógico (QL) procura definir os principais parâmetros de um projeto em uma matriz que contém quatro colunas e quatro níveis. Nestes 16 campos são preenchidas, de forma resumida, as informações relevantes sobre o projeto, como objetivos, resultados esperados, os respectivos indicadores que estabelecem metas quantitativas e qualitativas, as fontes onde as informações relevantes podem ser encontradas e fatores externos que representam riscos e que precisam ser monitorados. A aplicação do QL é mais apropriada, porém não exclusiva, em projetos de desenvolvimento, sejam de caráter público e de cunho social, sejam projetos de desenvolvimento organizacional.

A elaboração do Quadro Lógico (Tabela 1) permitiu a apresentação sistemática, lógica e sucinta do desenho da proposta previamente a análise da sua viabilidade. Foi usado em todo o ciclo do projeto e elaborado de forma participativa. Baseado em uma lógica vertical que torna clara a razão pela qual o projeto foi concebido e como será executado, o Quadro Lógico permitiu demonstrar que os resultados da proposta são claros, realistas e verificáveis. 


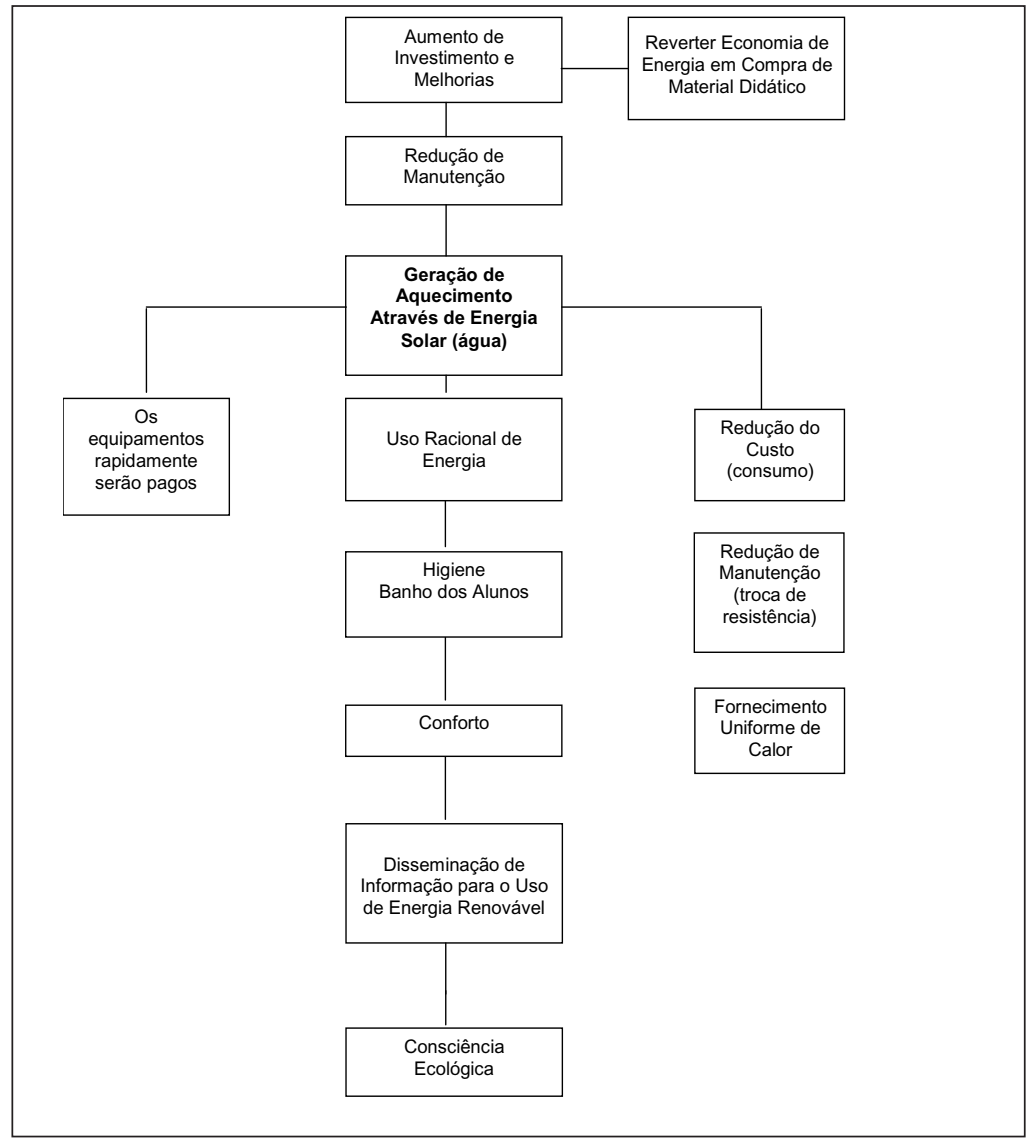

Tabela 1. Quadro Lógico

\begin{tabular}{|c|c|c|c|}
\hline Lógica da Intervenção & Indicadores & Fontes & Suposições \\
\hline $\begin{array}{l}\text { Objetivo Superior: } \\
\text { Adoção de medidas sustentáveis } \\
\text { na administração pública. }\end{array}$ & $\begin{array}{l}\text { Maior economia de } \\
\text { energia elétrica (cerca de } \\
80 \% \text { a } 81 \% \text { pormês). }\end{array}$ & $\begin{array}{l}\text { Ministério de Minas e } \\
\text { Energia. } \\
\text { Cepel } \\
\text { Empresas Especializadas } \\
\text { Abrava } \\
\text { Dasol } \\
\text { Internet }\end{array}$ & $\begin{array}{l}\text { Adoção de outra medida } \\
\text { sustentável de mesmo } \\
\text { impacto }\end{array}$ \\
\hline $\begin{array}{l}\text { Objetivo do Projeto: } \\
\text { Substituir o uso de energia } \\
\text { elétrica dos chuveiros por } \\
\text { aquecimento solar, reduzindo o } \\
\text { gasto de energia na creche do } \\
\text { município. }\end{array}$ & $\begin{array}{l}k=(t \times P) / 1000 \\
k=\text { kilowatt } \\
t=\text { tempo de banho } \\
P=\text { potência do chuveiro }\end{array}$ & Conta de energia elétrica & $\begin{array}{l}\text { Não aceitação do projeto } \\
\text { pelo gestor. } \\
\text { Não aceitação pela diretora } \\
\text { dacreche. } \\
\text { Não aceitação pelos } \\
\text { servidores que darão o } \\
\text { banho. }\end{array}$ \\
\hline $\begin{array}{l}\text { Resultados: } \\
\text { Aprovado pelo Gestor público. } \\
\text { Equipamentos adquiridos e } \\
\text { instalados na creche } \\
\text { Orientação às pessoas que } \\
\text { darãoobanho. } \\
\text {-Servidores instruídos e } \\
\text { conscientizados através de } \\
\text { divulgação sobre o uso de } \\
\text { energia sustentável. }\end{array}$ & & Relatório do projeto & $\begin{array}{l}\text { Atraso no processolicitatório } \\
\text { Descumprimento de } \\
\text { contratos } \\
\text { Atraso na entrega. }\end{array}$ \\
\hline
\end{tabular}

Figura 3. Árvore de Objetivos

Revista Eletrônica TECCEN, Vassouras, v. 3, n. 3, p. 7-16, jul./set., 2010 
Adicionalmente, foi elaborada a Carta do Projeto, que é o documento técnico que delineou as orientações básicas e a filosofia do projeto. Esta foi a base de referência para a tomada de decisões, tida como o produto final da fase de concepção da proposta. Para a visualização das atividades a serem realizadas, o WBS (Tabela 2) apresentou a estrutura analítica do trabalho e decompôs a proposta em atividades mensuráveis e controláveis.

Tabela 2. Work Breakdown Structure.

\section{Work Breakdown Structure}

1. Apresentação do projeto para o gestor

1.1 Agendar com o prefeito

1.2 Reunião

1.3 Aprovação

2. Levantamento de preço

2.1 Licitação

2.2 Contratação da empresa

3. Instalação

3.1 Acompanhamento

3.2 Aceite

4. Informação e orientação para o uso sustentável de energia e nova tecnologia

4.1 Divulgação para comunidade do uso de energia renovável

O sistema de aquecimento residencial de água por energia solar mais indicado é o que ocorre por circulação natural ou termossifão, pela sua simplicidade, confiabilidade e por necessitar de pouca manutenção. A circulação ocorre devido à diferença de densidade entre a água fria e a água quente, por convecção. Suas vantagens são as de não consumir energia elétrica, não causar poluição e demandar pouca manutenção, pois esta se retringe à limpeza dos vidros que revestem os coletores. (Lima, 2003)

O correto dimensionamento do sistema de aquecimento é decisivo para que os objetivos possam ser atingidos. (Arruda, 2004). Um bom equipamento instalado corretamente, mas subdimensionado para as necessidades reais de utilização de água quente poderá trazer diversos transtornos ao usuário. Nas residências, para banho, lavanderia e limpeza, a temperatura requerida da água é de $60{ }^{\circ} \mathrm{C}$ e o consumo de $50 \mathrm{~L}$ pessoa ${ }^{-1} / \mathrm{dia}^{-1}$. (Cepel, 2005). De acordo com este autor, a área de coletores do sistema de aquecimento de água por energia solar necessária pode ser calculada pela equação 1 a seguir:

$$
\mathrm{S}=\mathrm{Q} \mathrm{I}^{-1} \eta^{-1}
$$

onde, $\mathrm{S}$ é a área em $\mathrm{m}^{2}$, I é a intensidade de radiação solar em $\mathrm{kWh}\left(\mathrm{m}^{2} \mathrm{dia}^{-1}\right)$ e $\eta$ é o rendimento do aproveitamento da energia solar, estimado para fins práticos em $50 \%$. 
Adicionalmente, a quantidade de calor requerida será (Equação 2):

$$
\mathrm{Q}=\mathrm{m} \mathrm{c} \Delta \mathrm{T}
$$

onde $\mathrm{m}$ é a massa de água, c é o calor específico da água $\left(1 \mathrm{kcal} \mathrm{kg}^{-1}{ }^{\circ} \mathrm{C}^{-1}\right)$ e $\Delta \mathrm{T}$ é a variação de temperatura.

Como neste estudo tratou-se, especificamente, de chuveiro elétrico com potência (P) de 5400 watts e um tempo (t) estimado de banho de dez minutos por dia, o tempo acumulado no mês foi de 300 minutos ou 5 h. A simples multiplicação dos valores anteriormente citados mostrou que a energia consumida pelo chuveiro no período considerado foi de 27 $\mathrm{kWh}$.

Considerando-se, ainda, a necessidade de 85 banhos por mês ( 78 banhos de alunos e 07 banhos de funcionários), totalizam-se $425 \mathrm{~h}$ de uso do chuveiro elétrico/mês. Sendo a potência do chuveiro da creche igual a $5400 \mathrm{~W}$, alocou-se um total de $2295 \mathrm{kWh} / \mathrm{mês}$. Essa demanda de energia tem um custo mensal de $\mathrm{R} \$ 1028,16$ ( $\mathrm{R} \$ 0,448$ por cada $\mathrm{kW} / \mathrm{h}$ ).

$\mathrm{O}$ custo da energia elétrica da creche é, em média, de R $\$ 1258,00$. A simples análise dos valores mostra que após a instalação do sistema proposto neste projeto, pode-se esperar uma economia de cerca de $80 \%$. O estudo demonstra, portanto, a sustentabilidade desta proposta.

\section{Conclusões}

Atualmente, uma das principais preocupações da humanidade são as questões ambientais, especialmente em relação ao uso de energia elétrica.

A energia solar é uma excelente alternativa para suprir o consumo de água quente, pois além de vir de fonte inesgotável, miniminiza o problema de emissão de dióxido de carbono, gerado pela queima de combustíveis fósseis na produção de energia. (Hudson; Markell, 1985)

Por outro lado, o custo total da implantação do sistema de aquecimento solar para a creche Leon Gilson mostrou-se bastante elevado (cerca de R \$27500,00 conforme cotação realizada no ano de 2010), uma vez que incluiu a adequação das instalações físicas da creche, o custo com o gerente do projeto e a instalação dos equipamentos. A priori, esse valor pode fragilizar a proposta, mas o projeto demonstrou que a implantação destas ações é capaz de, em médio prazo, gerar economia suficiente para cobrir o custo inicial.

Conclui-se, portanto, que no âmbito da administração pública, a instalação de aquecedores solares em creches municipais seria uma opção viável, já, que comprovadamente, pode reduzir custos associados ao aquecimento da água, principalmente, daquela utilizada para o banho dos alunos e funcionários. Adicionalmente, a utilização das ferramentas GPD e WBS se mostrou fundamental para subsidiar e organizar os estudos iniciais referentes a este tipo de proposta. 


\section{Referências}

Abrava. Associação Brasileira de Refrigeração, Ar Condicionado, Ventilação e Aquecimento. (2009). Disponível em: http://www.abrava.com.br. Acesso em: maio 2009.

Arruda, L.B. (2004). Operação de sistemas de aquecimento solar de água com controle de vazões em coletores planos. Tese de Doutorado em Engenharia. Escola Politécnica, Universidade de São Paulo, São Paulo.

Brasil/ Ministério de Minas e Energia. Eletrobrás. (2009). Programa Nacional de Conservação de Energia Elétrica (PROCEL). Brasília, 1985. Disponível em: http:// www.eletrobras.- gov.br/procel. Acesso em: 12 de maio 2009.

Cepel. (2005). Coletânea de Artigos: Energia Solar e Eólica. Volume 2. Rio de Janeiro.

Dasol - Departamento Nacional de Aquecimento Solar. (2009). Disponível em: http:// www.dasol.com. br. Acesso em 12 de maio de 2009.

Eletrobras. (2009). Disponível em:<http://www.eletrobras.gov.br,> acesso em 12 de maio de 2009.

Energia Hoje, (2009). CRECHES COM AQUECIMENTO SOLAR, Disponível em: $<$ www.energiahoje.com>, Acesso em 12 de maio de 2009.

Hudson, L.G.; Markell, J. (1985). Solar technology. Reston: Reston Publishing Company.

Lima, J.B.A. (2003). Otimização de sistema de aquecimento solar de água em edificações residenciais unifamiliares utilizando o programa TRNSYS. Dissertação de Mestrado em Engenharia. Escola Politécnica, Universidade de São Paulo, São Paulo.

Pereira, E. B.; MARTINS, F. R.; ABREU, S. L.; RÜTHER, R. (2006). Atlas Brasileiro de Energia Solar. São José dos Campos: INPE, 2006.

Pfeiffer, Peter. (2005). Método Gerenciamento de Processo de Desenvolvimento. Brasport. Rio de Janeiro.

Secretaria Municipal de Educação. (2009). Comunicação oral. Vassouras.

Soletrol. (2009). Disponível em: <http://www.soletrol.com.br,> Acesso em 12 de maio de 2009.

Vitae Civilis, (2009). São Paulo Terá Aquecimento Solar em Novas Edificações, Disponível em http:// www.vitaecivilis.org.br Acesso em 12 de maio de 2009. 